\title{
LA PROTECCIÓN DE DATOS COMO FRONTERA DEL DERECHO DE ACCESO A LA INFORMACIÓN EN LA LEGISLACIÓN CHILENA
}

\author{
Gladys Camacho Cépeda \\ Universidad de Chile \\ gcamacho@derecho.uchile.cl
}

\begin{abstract}
RESUMEN
El 20 de abril de 2009 entró en vigencia en Chile la Ley de Transparencia, que asegura a los ciudadanos el acceso a la información pública. Si bien el balance de este régimen es positivo, importa analizar los núcleos de conflictos que se generan cuando se deben conciliar derechos e intereses jurídicos tutelados por el ordenamiento jurídico chileno, como la protección de la vida privada y datos personales. El artículo analiza la situación de la protección de datos personales en el ordenamiento jurídico chileno. Por una parte, argumenta que el derecho a la protección de los datos personales traspasa la clásica división del ámbito de lo público y lo privado, pues en ambos campos es necesario cautelarlo. Por otro lado, el trabajo busca aportar al debate para la construcción de estándares de actuación para los organismos públicos que permitan compatibilizar la transparencia con la protección de datos personales.
\end{abstract}

Palabras Clave: Derecho de acceso a la información pública, Protección de datos privados, Transparencia, Derecho Administrativo, Chile. 


\title{
DATA PROTECTION AS BOUNDARY TO THE RIGHT TO ACCESS INFORMATION UNDER CHILEAN LAW
}

\begin{abstract}
ABRSTRACT
On April 20, 2009, the Transparency Act entered into force in Chile, ensuring citizens the access to public information. Although the balance of this system is positive, it is important to analyse the heart of conflicts which arise when needing to reconcile legal interests and rights guarded by Chilean law, such as the protection of privacy and personal data. The paper analyses the status of the protection of personal data in the Chilean legal system. Firstly, it argues that the right to protection of personal data transcends the classical division between public and private scope, because in both fields it needs to be guarded. Secondly, the abstract seeks to contribute to the debate for the construction of performance standards for public organizations to enable reconciling transparency with the protection of personal data.
\end{abstract}

Keywords: Right to Access Public Information, Protection of Private Data, Transparency, Administrative Law, Chile. 


\section{INTRODUCCIÓN}

Existe una opinión positiva sobre los significativos avances que en Chile se han propiciado en los últimos ańos en materia de transparencia que permiten evaluar satisfactoriamente la aplicación de la Ley N. ${ }^{\circ} 20.285$ de Acceso a la Información Pública. El régimen chileno de acceso a la información es uno de los que establecen márgenes más amplios para el ejercicio del derecho y así es reconocido en el ámbito internacional, superando con creces el limitado sistema previo que fue introducido por la Ley N. ${ }^{\circ} 19.623$, de Probidad Administrativa, en 1999.

El reconocimiento del derecho de acceso a la información pública constituye uno de los cambios normativos que afecta directamente la organización y la práctica administrativa. La Ley N. ${ }^{\circ} 20.285$, sobre Acceso a la Información Pública (en adelante Ley de Transparencia), constituye una innovación normativa cuya sanción se inscribe en los esfuerzos por dar lugar a un indudable cambio de paradigma de la actividad administrativa sustentado en la efectividad de los principios de probidad y transparencia públicas. La citada ley constituye la culminación de un largo y difícil camino recorrido con el objeto de afirmar una política de transparencia a nivel no sólo de la Administración Pública sino extendida también a cualquier órgano-poder del Estado.

La institucionalización definitiva del acceso a la información pública como derecho en Chile ha debido sortear múltiples trabas en los últimos tiempos, pero eso no constituye ninguna novedad, como se puede advertir de los procesos que dan cuenta de lo difícil que ha sido en países de vasta tradición democrática instaurar una cultura de transparencia y lo vigilante que se aconseja estar para perseverar en este propósito. Es así como respetables organizaciones no gubernamentales han surgido con este propósito.

Para que el principio de transparencia pueda hacerse paso hubo de respaldarse por la reforma constitucional más importante llevada a cabo en democracia (1990 en adelante) y que se formalizó por la Ley N. ${ }^{\circ} 20.050$ de 2005. Esta reforma introdujo un nuevo texto en el artículo 8 contenido en el Capítulo I de las Bases de la Institucionalidad, el cual ha propiciado la renovación total del régimen jurídico de la transparencia pública que hasta entonces venía rigiendo.

Si bien desde el 20 de abril de 2009, fecha en que entró en vigencia el régimen actual de transparencia pública el balance es positivo, importa analizar precisamente los núcleos de conflictos que se generan cuando se deben conciliar derechos e intereses jurídicos tutelados por el ordenamiento 
jurídico chileno. En este caso nos referiremos a la protección de la vida privada que está reconocida en la Carta Política y a la protección de datos personales como derecho conexo a ésta. Todo ello en un contexto en el que las nuevas tecnologías de la información ejercen un efecto multiplicador de la intensidad con la que se pueden afectar dichos derechos.

\section{LA NECESIDAD DE REVISAR LA FUNDAMENTACIÓN DEL DERECHO A LA PROTECCIÓN DE DATOS BASADO EN EL DERECHO A LA PROTECCIÓN DE LA VIDA PRIVADA}

En una primera instancia, parece adecuado abordar si la común comprensión del derecho a la protección de datos dentro del derecho a la privacidad es lo que corresponde o es una simplificación que lejos de favorecer una protección adecuada tiene el riesgo de debilitar el derecho confundiéndolo dentro de la multiplicidad de significados que tiene la palabra privacidad (Corral 2000).

Si bien el legislador en la Ley N. ${ }^{\circ} 19.628$ sobre Protección de la Vida Privada y Datos de Carácter Privado hace la identificación entre derecho a la protección de la vida privada y el derecho a la protección de los datos personales (también reconocido como derecho a la autodeterminación informativa), las transformaciones de la realidad social propiciadas por el desarrollo de las nuevas tecnologías, hacen notoriamente insuficiente este planteamiento por cuanto la problemática de la protección de datos personales desborda palmariamente la protección de la privacidad. Son muchos los esfuerzos empeñados y las dificultades que encuentra la tarea de definir el núcleo de la noción vida privada o privacidad, máxime que este concepto no sólo varía en el espacio temporal sino que es distinto según el espacio cultural y geográfico en el que se pretende delimitar. Esta característica lleva a confundir la noción o a encontrar que ésta comprende diversos derechos de la persona cuyos sistemas jurídicos de protección no son iguales. Éste es el caso de los derechos: a la intimidad, el honor, a la imagen, entre otros, atomizando la aplicación del concepto en direcciones que no resultan convergentes, lo que dificulta la función de esclarecimiento que cumplen las definiciones en la aplicación del Derecho. Desde su primera formulación en el ámbito anglosajón por Brandeis la protección de la privacidad se manifiesta por el rechazo de toda intromisión no consentida en la vida privada no sólo del Estado y otras personas sino especialmente, de los medios de comunicación, lo que genéricamente se engloba en la célebre frase "el derecho a ser dejado solo o a no ser molestado (the right to be let alone) ${ }^{1}$. Si bien el derecho a no ser molestado es una expresión muy propia del liberalismo clásico que se asocia

1 Sobre la autoría de la célebre frase, véase Sparkes (1981). 
al derecho de la persona a proteger su intimidad lo que habilita a su titular para rechazar cualquier intromisión sobre el ámbito de su vida privada que es inaccesible a los demás salvo que medie su expreso consentimiento. En el marco del liberalismo democrático el derecho a la intimidad no sólo supone el rechazo frente a cualquier perturbación procedente del exterior, sino también la potestad para disponer acerca del flujo de información que trascienda a la voluntad de su titular, sobre aspectos relativos a su círculo privado (Carillo 2003).

Con todo, acogiendo la perspectiva de la delimitación estricta propuesta por Corral (2000), el punto de base en la definición de privacidad se encuentra en la pretensión y necesidad que lo que ésta necesariamente conlleva es tener un ámbito reservado y ajeno a la mirada y acceso de los otros, elemento que el citado autor denomina intromisión cognoscitiva, vertiente que alude como el "interés de que un tercero no se introduzca en espacios de vida personal que no le conciernen" de tal manera que obtenga conocimiento de hechos personales (Corral 2000: 343-344). Lo que se complementa con la proscripción de interferencias a la privacidad consistentes en la difusión que comprende los supuestos en los que el resultado cognoscitivo de la intromisión viene a ser revelado a otra u otras personas.

Ahora bien, para determinar la corrección de apelar al derecho a la protección de la privacidad y así fundar en ésta el derecho a la protección de datos personales, se ha de tener en cuenta el contexto actual caracterizado por el auge de las redes sociales que ha debilitado el derecho a la autodeterminación informativa. Este nuevo contexto ha propiciado que la esfera de privacidad disminuya sustancialmente, pues los titulares de los antecedentes nominativos (fotos, datos personales, opiniones, entre otros), han otorgado contractualmente su autorización para realizar tratamiento de sus datos y disponer de ellos. Esto ha sido consecuencia de la configuración de las redes sociales lo que ha llevado a impulsar que sus usuarios compartan públicamente abundante información personal conduciéndolos, por defecto, a una posición de revelar todo. Las políticas de privacidad de Facebook, Twitter, Hi5 y otros, permiten compartir información personal (como nombre, género, foto de perfil y hasta la ubicación del usuario) con terceros que bien pueden ser no sólo personas naturales sino empresas como, por ejemplo, aquellas que desarrollan aplicaciones, a las cuales la información sería entregada automáticamente, sin preguntar por autorización. En este contexto, la posición de los jóvenes cobra una especial fragilidad, pues se advierte que estos no son conscientes que sus perfiles personales están siendo usados para fines comerciales. 
En consecuencia, el auge de las redes sociales ha hecho evidente que el derecho a la protección de datos personales, entendida ésta como una prerrogativa orientada a dar una protección efectiva a la persona, exige que, necesariamente, ella sea configurada como un derecho autónomo e independiente del derecho a la vida privada, pues el ámbito de protección de la privacidad como referente para la protección de la autodeterminación informativa resulta por demás limitado.

Los poderes que el derecho de protección de datos atribuye a su titular no deben estar condicionados o menoscabados como consecuencia de una decisión de publicitar información personal, lo que conllevaría a no calificar dicha información como privada ${ }^{2}$. Con independencia de esta decisión el titular de los datos debe poder exigir, a quien sea el responsable de un banco de datos, conocer la información de los datos sobre su persona, el tratamiento del que han sido objeto, la finalidad de éste, la individualización del destinatario de la transmisión en el caso que se haya producido, el propósito del almacenamiento, su rectificación o anulación, entre otras.

Esta conclusión, lleva a revisar cual sería el fundamento del derecho a la protección de datos en el ordenamiento jurídico chileno y la respuesta es que no encontramos un precepto que explícitamente se refiera a este derecho en la Carta Política.

Sin embargo, a pesar de esta carencia de texto legal expreso como lo ha subrayado el Tribunal Constitucional alemán, el derecho a la protección de datos se conecta directamente con la razón primera del ordenamiento, cual es la persona humana, la que se constituye en la figura principal del

2 Los poderes que la protección de datos personales proporciona a su titular se fundan en los principios que debe respetar el tratamiento de datos personales, los que están contenidos endiversos cuerpos normativos que constituyen nuestros referentes más cercanos aprobados en el marco de la Organización de las Naciones Unidas (ONU), la Organización para la Cooperación y el Desarrollo Económico (OCDE) y la Unión Europea (UE), los que sucintamente pueden identificarse como los siguientes:1) principio de lealtad (el tratamiento de los datos no debe producir discriminaciones arbitrarias para el titular de los datos y debe hacerse con sujeción al ordenamiento jurídico que cautela los derechos y libertades de las personas); 2) principio de finalidad (limita el tratamiento de datos a los objetivos explícitos y legítimos perseguidos); 3) principio de proporcionalidad (circunscribe tanto la colección como el tratamiento de datos a lo que es adecuado para el fin perseguido evitando los excesos); 4) principio de calidad (exige al responsable de los ficheros de datos que estos sean exactos, completos y actualizados); 5) principio de transparencia (exige que el responsable del tratamiento de los datos entregue con carácter previo a los titulares de los datos toda la información relevante tales como su identidad, la finalidad del tratamiento, los destinatarios a los que se transmitirán los datos, entre otros). Se agregan los principios ARCO (acceso, rectificación y oposición), que suponen reconocer los derechos de los titulares a acceder, rectificar y oponerse al tratamiento de sus datos). A este respecto, véase Serna de la Bilbao (2011) y Arrieta (2009). 
Derecho. Es así que en el régimen constitucional "El Estado está al servicio de la persona humana” (inciso 3, artículo 1, Constitución Política de la República de Chile). Consiguientemente, los derechos fundamentales de la persona traen causa en su dignidad, de la cual se derivan los valores: libertad, igualdad, no discriminación, honor, intimidad, privacidad, entre otros. Como señala Figueroa (1998: 23), "el fundamento primero de todos los derechos esenciales de las personas naturales, estén consagrados en Tratados Internacionales, en Constituciones Políticas o en Códigos Penales o Civiles, es su dignidad".

Fundar el derecho de protección de datos en la dignidad de la persona, que como se ha señalado es el valor fundamental que garantiza desde su primer articulado la Constitución Política, es congruente con postular que aquel derecho reúne las exigencias para ser reconocido como de naturaleza fundamental, pues expresa los valores que la dignidad de la persona exige que se le reconozcan a la persona.

En especial, la protección de datos personales sirve a la efectividad de los valores constitucionales de libertad e igualdad de las personas. Como señala Figueoa (1998: 23-24), al reflexionar sobre el fundamento suprajurídico de los derechos humanos:

La colectividad humana es portadora de valores, los cuales varían históricamente conforme a los intereses de las épocas y dan contenido a las culturas. Estos valores se expresan en normas éticas y jurídicas, las cuales presuponen la existencia de tales valores. El fundamento de los derechos humanos es, en consecuencia, un fundamento éticoaxiológico (o valorativo). Es el valor que asignamos al hombre como tal y la concepción que tenemos de su dignidad intrínseca, los que fundamentan estos derechos humanos.

Por ello, en materia de protección de datos, en conexión directa con la preocupación por los derechos humanos, las organizaciones internacionales como la ONU, la UE y la OCDE, han establecido estándares que son un importante referente para Chile en esta materia. Esos estándares de referencia están contenidos en diversos instrumentos internacionales

Consiguientemente, la protección de los datos personales no sólo se debe fundamentar y configurar desde el derecho a la vida privada o intimidad sino desde su necesaria comprensión como uno los derechos que derivan de la dignidad de la persona a cuya protección se avoca el Ordenamiento en su integridad. Así, junto al derecho a la vida, al derecho a la integridad física, al derecho a la integridad psíquica, el derecho a vivir en un medio ambiente libre de contaminación, entre otros, el derecho a la protección 
de datos hace realidad la máxima que establece "el Derecho existe para el hombre y es creación del hombre" (Figueroa 1998: 21), colaborando en la función última que tiene el Derecho de otorgar una protección jurídica integral a la persona humana.

\section{LOS ELEMENTOS QUE HAN PROPICIADO EL DESIGUAL DESARROLLO DE LA PROTECCIÓN DE DATOS Y EL DERECHO DE ACCESO A LA INFORMACIÓN PÚBLICA}

Los avances significativos en materia de transparencia han provenido principalmente de dos vertientes de exigencias que han confluido positivamente en su potenciación. De un lado, la profundización del sistema democrático en Chile, aspiración latente que expresa la maduración como sociedad, y de otro lado, los requerimientos para el buen funcionamiento de los mercados en un mundo globalizado, lo que ha traído como consecuencia el énfasis en la lucha contra la corrupción, pues ésta falsea la libre competencia y genera graves ineficiencias económicas.

Así, la transparencia pública ha sido reclamada como instrumento para reforzar la democracia en Chile, prevenir los abusos de poder, reconociéndole su gran eficacia en la lucha contra la corrupción. Los objetivos gubernamentales desde el retorno a la democracia han tenido en el desarrollo económico una de sus prioridades más importantes, muestra de lo cual es el relativo éxito económico que exhibe el país en sus cuentas nacionales. Para lograr esta meta, la economía abierta y la resuelta política de incorporación a grandes mercados han impulsado que Chile haya estado dispuesto a suscribir los compromisos colaterales asociados a los tratados de libre comercio y haya emprendido su implementación de manera efectiva. A este respecto, el ingreso a la OCDE en 2009 no sólo ha significado la suscripción de la Convención para Combatir el Cohecho de Funcionarios Públicos Extranjeros en Transacciones Comerciales Internacionales sino la modificación del ordenamiento en materias importantes entre las cuales destacan, las disposiciones legales vinculadas a los objetivos de la lucha contra la corrupción (por ejemplo, regulación de las compras públicas, procedimiento administrativo, reforma de otros delitos funcionarios, entre otros).

En esta línea, se inscribe el régimen de acceso a la información pública contenido en la Ley $\mathrm{N}^{\circ}$ 20.285, debido al cual los informes de las misiones examinadores del grupo de trabajo sobre corrupción de la OCDE, finalmente fueron positivos, aceptando acreditar el sistema de transparencia chileno como uno que reúne suficientemente las exigencias que los países miembros deben incorporar. 
Desde otra perspectiva, la de la eficiencia del mercado y el impulso a las actividades económicas, sin embargo, el derecho a la protección de datos no tuvo igual suerte que la transparencia pública. El legislador al sancionar la Ley N. ${ }^{\circ} 19.628$, sobre protección de datos personales, se inclinó por el objetivo de entregar un marco normativo que favorezca la actividad económica de tratamiento de datos, cuyo mercado era emergente y promisorio, relegando a un segundo plano, el acento en la garantía de los derechos de las personas (véase Arrieta 2009). Por ello, se puede sostener que la Ley N. ${ }^{\circ} 19.628$ se limita a regular el mercado de los datos personales eliminando o disminuyendo en lo posible los obstáculos para la actividad, pero no ha puesto su foco en la protección de los derechos de los titulares de esos datos, lo que acarrea la carencia de una adecuada protección de los datos personales que esté en sintonía con lo que los socios comerciales de países más avanzados exigen a Chile.

A este respecto, una de las mayores debilidades del régimen de protección de datos radica en carecer de instrumentos jurídicos (recursos $\mathrm{u}$ acciones) de defensa ágiles y expeditos, sanciones claras a los infractores, así como de una autoridad especializada que se avoque a garantizar su buen funcionamiento y que cautele oportunamente los abusos en el tratamiento de datos y los pueda sancionar oportunamente.

Sin embargo, esta mirada del legislador ha sido de muy corto alcance, y no sólo ya en algunos casos está entrabando las relaciones comerciales sino que puede conllevar el riesgo de dejar escapar la oportunidad para capturar industrias de aplicación de tecnologías como los llamados servicios globales (también conocidos como offshoring), por carecer de un adecuado ambiente institucional de protección de datos. Sólo la comprensión de la protección de datos como un derecho de las personas que puede transformarse en un activo corporativo en lugar de percibir las exigencias que comporta la vigencia del derecho en una carga regulatoria, permitirán desarrollar las certezas que requieren los negocios asociados al flujo transfronterizo de datos (Cruz 2011).

La significación creciente que esta actividad ha cobrado en el país, se expresa en el volumen de negocios que comprenden los servicios globales, cuya tasa de crecimiento bordea el 15\% anual y moviliza más de US\$ 192.000.000.000 en el mercado mundial. En Chile esta industria, igualmente, ha tenido un crecimiento expansivo sostenido. De acuerdo a un estudio de la Corporación de Fomento de la Producción (CORFO), en 2006 los ingresos por exportaciones vinculadas a esta actividad ascendían a US\$ 200.000.000 mientras que en 2008 lograron alcanzar los US\$ 938.000.000. A la par, los agentes vinculados a esta actividad económica están representados por un grupo aproximado de 430 empresas entre las 
que las empresas locales son la mayoría (70\%), pero las firmas extranjeras son las que generan el 66\% de los más ingresos. Asimismo, esta industria ha generado 20.000 plazas de empleo (IDC 2009). De este modo, el offshoring requiere para su desarrollo que el país esté dotado de un buen ambiente institucional para potenciar un marco legal garantista respecto del tratamiento de la información y el procesamiento de datos (Ferreiro 2009).

\section{PROBLEMAS DE LA APLICACIÓN DE LA LEY DE PROTECCIÓN DE LA VIDA PRIVADA Y DATOS DE CARÁCTER PRIVADO}

\section{La naturaleza ordinaria de la Ley de Protección de la Vida Privada y Datos de Carácter Privado}

Postulando que la protección de datos personales es un nuevo derecho que se abre paso más allá del derecho a la privacidad - por estar conectado directamente con los valores constitucionales de dignidad de la persona, igualdad y no discriminación-, se puede concluir que la Ley N. ${ }^{\circ} 19.628$ está llamada a cumplir una importante función constitucional para cautelar la vigencia de este nuevo derecho. En consecuencia, la aplicación de la Ley N.`19.628 debe conectarse armónicamente con la excepción a la publicidad que establece la Constitución Política en su artículo 8 en lo que se refiere a la causal de afectación de los derechos de las personas. Causal que permite fundar el secreto o reserva de datos personales requeridos a la autoridad administrativa en caso que su publicidad afecte los derechos de sus titulares.

En ese sentido, la calidad de ley ordinaria de la Ley N. ${ }^{\circ} 19.628$ no es determinante de su ámbito ni de la intensidad de la protección que ella despliega. En su lugar, el criterio para determinar qué es lo que queda comprendido bajo su resguardo es lo que ésta define como datos de carácter personal, pues cumple una función constitucional de garantía de la persona a través de la protección de sus datos. Así, lo que la Ley N. 19.628 reconoce como datos de carácter personal son "los relativos a cualquier información, concerniente a personas naturales, identificadas o identificables" (letra f, artículo 2). Aún más, en la misma línea, el legislador confiere una protección reforzada a aquellos datos personales que la ley define como datos sensibles comprendiendo en esta noción a

[...] los datos personales que se refieren a las características físicas o morales de las personas o a hechos o circunstancias de su vida privada o intimidad, tales como los hábitos personales, el origen racial, las ideologías y opiniones políticas, las creencias o convicciones religiosas, los estados de salud físicos o psíquicos y la vida sexual 
(letra g, artículo 2).

De este modo, la presencia de "datos de carácter personal" (particularmente, cuando se tratan de datos sensibles) es determinante para invocar la aplicación de la Le yN. ${ }^{\circ} 19.628$ en cualquier ámbito. Ello por cuanto es la función constitucional que esta ley viene a cumplir la que debe guiar para resolver las dudas sobre cuándo debe operar, con independencia de si la regulación de determinados ámbitos ha sido sancionada por una ley de quórum calificado o una ley orgánica constitucional. Como sabemos, no existe una jerarquía de leyes, la exigencia de quórums de aprobación más altos obedece a una decisión del constituyente en determinadas materias de reserva de ley y sólo constituye un requisito previo para la correcta aprobación de la norma legal que incide en su validez, pero una vez sancionada dicha norma se incorpora al ordenamiento jurídico en el rango legal. En el ordenamiento jurídico chileno mal podemos afirmar una desigualdad jerárquica normativa tratándose de normas legales y de ahí extraer consecuencias sobre la asimétrica protección de derechos fundamentales. En ese sentido, discrepamos de la argumentación del Consejo para la Transparencia para excluir la aplicación de la Ley N. ${ }^{\circ}$ 19.628 sosteniendo lo siguiente:

Este Consejo estima que existiendo una ley orgánica constitucional que declara que la información contenida en los registros electorales es pública -información que es la misma que contiene el padrón electoral computacional solicitado en la especie- no se puede requerir al órgano reclamado que tarje aquellos datos personales, ni aún bajo el amparo de la Ley N. ${ }^{\circ} 19.628$, sobre protección de datos personales, ya que ésta fue aprobada con un quórum de ley simple que impide a este Consejo estimar que pudiese haber derogado tácitamente a una norma aprobada con quórum orgánico constitucional, como el art. 25 de la Ley N. ${ }^{\circ} 18.556$ (considerando N. ${ }^{\circ} 15$, decisión de amparo N. ${ }^{\circ}$ C407-09).

A mayor abundamiento, se puede postular que algunas disposiciones de la Ley N. ${ }^{\circ} 19.628$ que permiten fundamentar la excepción a la publicidad reúnen la exigencia de quórum calificado por aplicación del artículo 1 de las disposiciones transitorias de la Ley N. ${ }^{\circ} 20.285$, en virtud del cual, se entiende que cumplen con esta exigencia los preceptos legales dictados con anterioridad a la Ley de Reforma Constitucional N. 20.050 que establecen secreto o reserva respecto de las causales que señala el artículo 8 de la Constitución Política. 


\section{La función matizadora de la Ley de Protección de la Vida Privada y Datos de Carácter Privado del derecho al acceso a la información PÚBLICA}

Complementariamente, la interpretación que aquí se postula tiene también otra clara consecuencia en la extensión del ámbito de aplicación de la Ley N. ${ }^{\circ} 19.628$ con evidente incidencia en el régimen de transparencia. Así, en nuestra opinión, la autoridad administrativa requerida de información podría fundamentar una denegación de información fundándose en la Ley $\mathrm{N}^{\circ} 19.628$ a la que puede acudir por remisión del artículo $2, \mathrm{~N} .^{\circ} 2$ de la Ley de Transparencia. Así, por ejemplo, la aplicación de la Ley N. ${ }^{\circ}$ 19.628 puede dar lugar a una interpretación matizada de la disposición contenida en el artículo 20 de la Ley de Transparencia, que finalmente establece que de no oponerse fundada y oportunamente, se entiende que el tercero afectado accede a que se entregue la información, lo que tiene como consecuencia jurídica que la autoridad estaría obligada a facilitar la información requerida. Ahora bien, tratándose de datos personales, la autoridad debe ante todo realizar un análisis de proporcionalidad a la luz de los derechos e intereses públicos confrontados y en particular, tratándose de datos sensibles la autoridad, invocando la Ley N. 19.628 -que contiene obligaciones plenamente vigentes para las autoridades responsables de bases de datos personales- debe denegar su entrega aun cuando el tercero afectado no se haya opuesto, pues le asiste la obligación legal de proteger los datos personales cuando su publicidad afecte los derechos de su titular. Mediante este análisis y ponderación de la situación, la autoridad requerida aplicará armónicamente el régimen de protección de datos con el derecho de acceso a la información pública considerando además que, ciertamente, esa decisión podrá ser revisada por el Consejo para la Transparencia quien es además el responsable debe velar por el adecuado cumplimiento de la Ley N. ${ }^{\circ} 19.628$.

En suma, por todo lo anteriormente señalado puede cabalmente sostenerse que la Ley $\mathrm{N} .^{\circ} 19.628$ reúne la calidad de ley de quórum calificado para efectos de poder fundar en ella una excepción a la publicidad por la causal de afectación de derechos de las personas.

\section{Las prescripciones de la Ley de Transparencia y su reglamento que refieren a la Ley de Protección de la Vida Privada y Datos de Carácter Privado}

Cuando de materia de excepciones a la publicidad se trata ha sido el constituyente el que ha remitido al legislador de quórum calificado la precisión de las causales que el artículo 8 de la Constitución Política dejó establecidas, entre las cuales se encuentra la excepción de reserva o secreto 
cuando "la publicidad afectare los derechos de las personas". En tal sentido, la Ley de Transparencia cumpliendo la decisión del constituyente, al regular el régimen de transparencia activa, ha buscado guardar congruencia con el régimen de protección de datos personales determinado por la Ley $\mathrm{N}$. 19.628. Así, por ejemplo, el artículo 7, letra i de la Ley de Transparencia, que se refiere a una de las obligaciones de transparencia activa, establece la reserva de informar en los sitios web los datos sensibles, esto es,

Los datos personales que se refieren a las características físicas o morales de las personas o a hechos o circunstancias de su vida privada o intimidad, tales como los hábitos personales, el origen social, las ideologías y opiniones políticas, las creencias o convicciones religiosas, los estados de salud físicos o psíquicos y la vida sexual.

En la misma línea, el Instructivo General N. 4, sobre Transparencia Activa, sancionado por el Consejo ordena aplicar el mismo criterio cuando se trata de la publicidad de los actos y resoluciones que tengan efectos sobre terceros (N. ${ }^{\circ} 1.7$ in fine) reconociendo la aplicación directa de los criterios contenidos en la Ley N. ${ }^{\circ} 19.628$.

En el campo de la transparencia pasiva (cuando se trata de atender solicitudes de información por parte de cualquier órgano de la Administración del Estado) no hay una referencia directa a la Ley de Protección de Datos de Carácter Personal, sin embargo, fácilmente podemos encontrar el fundamento para fundar un engranaje coherente con la aplicación de Ley N. ${ }^{\circ} 19.628$. A este respecto, la Ley de Transparencia, en su artículo $21, \mathrm{~N}^{\circ} 2$, precisa algunas de las circunstancias que califican dentro de esta excepción, cuales son, particularmente, "si la publicidad de la información afecte a las personas tratándose de... la esfera de su vida privada”. Asimismo, el N. 2 del artículo 7 del Reglamento del artículo 1 de la Ley N. ${ }^{\circ} 20.285$, aprobado por Decreto Supremo N. ${ }^{\circ} 13$, de 2 de marzo de 2009 , es muy claro en recoger la inspiración de la Ley $\mathrm{N} .^{\circ}$ 19.628 disponiendo que se podrá denegar total o parcialmente el acceso a la información "cuando su publicidad, comunicación o conocimiento afecte los derechos de las personas, particularmente tratándose de... la esfera de su vida privada, sus datos sensibles [...]”. En consecuencia, estas previsiones legales son las que facultan al Consejo para armonizar la aplicación de la Ley N. ${ }^{\circ} 19.628$ que se autodenomina de protección de la vida privada y establece el régimen de Protección de Datos de Carácter Personal, constituyéndose éste en un régimen especial que en lo que en este punto interesa obliga a los responsables de bases de datos y de su tratamiento en los organismos públicos a respetar las limitaciones que dicha norma legal dispone para la utilización de datos de carácter personal. A las citadas disposiciones legales habría que sumar la contenida en el artículo 
33, letra $m$ de la Ley de Transparencia, el cual encarga al Consejo para la Transparencia "velar por el adecuado cumplimiento de la Ley N. ${ }^{\circ} 19.628$, de protección de datos de carácter personal, por parte de los órganos de la Administración del Estado". Lo que ha permitido al Consejo, en una primera etapa, interpretar la ley en sede administrativa a través de sus decisiones y hacerse cargo de armonizar la aplicación del derecho de acceso a la información pública con el derecho a la protección de datos personales. A este respecto, han sido numerosos los pronunciamientos del Consejo que invocan las disposiciones de la Ley N. 19.628.

\section{LAS TENSIONES ENTRE LAS EXIGENCIAS QUE PROCEDEN DE DOS DERECHOS FUNDAMENTALES: LA PROTECCIÓN DE DATOS Y EL DERECHO DE ACCESO A LA INFORMACIÓN PÚBLICA A LA LUZ DE LA JURISPRUDENCIA}

Atendiendo a la efectividad del régimen de transparencia pública, en especial, a la demostrada eficacia del mecanismo de reclamación con el que se cuenta en los casos de denegación del derecho de acceso, eran del todo previsibles las tensiones que se han producido entre el derecho de acceso a información y la protección de datos personales.

Desde la entrada en vigencia de la Ley de Transparencia un buen número de reclamaciones que ha debido conocer el Consejo para la Transparencia han supuesto la confrontación de los dos bienes jurídicos: de un lado del derecho de acceso, y de otro lado, el derecho a la protección de datos. Desde un punto de vista cuantitativo, Rajevic (2011:150) ha señalado que

Cerca de la cuarta parte de las decisiones de fondo dictadas por el CPT [Consejo para la Transparencia] durante el último trimestre tuvieron que ver con datos personales en mayor o menor medida, esto es, una de cada cuatro, lo que en sede de acceso a la información es relativamente frecuente que deba aplicarse la Ley N. 19.628.

Por consiguiente, al Consejo para la Transparencia le ha correspondido realizar una labor de armonización y ponderación de estos valores jurídicos, lo que torna de especial interés analizar cómo ha venido cumpliendo esta labor.

Ciertamente, la competencia del Consejo para la Transparencia para cautelar la protección de datos en la esfera administrativa, está reconocida por el artículo 33, letra m de la Ley $\mathrm{N}^{\circ}{ }^{2} 20.285$, el cual atribuye a dicho Consejo la función de "velar por el adecuado cumplimiento de la Ley N. 19.628, de protección de datos de carácter personal por parte de los órganos de la Administración del Estado", por lo que en su intensa actividad de 
conocimiento y resolución de los reclamos en materia de transparencia, el Consejo ha debido enfrentarse numerosas veces a decisiones en las que ha debido ponderar el derecho de acceso a la información pública y el derecho a la protección de datos personales, inclinando la balanza en uno u en otro sentido.

En este contexto, para el presente trabajo lo que interesa es reflexionar sobre los criterios y fundamentos que ha expuesto el Consejo para la Transparencia en los casos que ha debido resolver cuando han estado estos dos derechos involucrados lo que permitirá ir construyendo un balance de su labor de armonización y ponderación de esos dos bienes jurídicos fundamentales.

\section{SOBRE LA TITULARIDAD DE LOS DATOS PERSONALES}

La Ley N.`19.628 define con precisión a quién corresponde la titularidad de los datos personales radicándola en "la persona natural a la que se refieren los datos de carácter personal” (letra ñ, artículo 2). Como ya se ha señalado esta noción es clave para indicarnos y delimitar la aplicación del régimen de protección de datos que esta ley contiene.

El ámbito de protección de los datos personales debe compatibilizarse con lo que define la Ley de Trasparencia en forma amplia como información pública. Según la Ley de Transparencia esta noción comprende:

[...] los actos y resoluciones de los órganos de la Administración del Estado, sus fundamentos, los documentos que les sirvan de sustento o complemento directo y esencial, y los procedimientos que se utilicen para su dictación, son públicos, salvo las excepciones que establece esta ley y las previstas en otras leyes de quórum calificado.

Asimismo, es pública la información elaborada con presupuesto público y toda otra información que obre en poder de los órganos de la Administración, cualquiera sea su formato, soporte, fecha de creación, origen, clasificación o procesamiento, a menos que esté sujeta a las excepciones señaladas (artículo 5).

En otra ocasión ya hemos tratado sobre los problemas del concepto de información pública, elemento clave para la aplicación del régimen de transparencia (Camacho 2010). Recapitulando a este respecto, se puede observar que de los artículos 5 y 10 de la Ley de Transparencia se desprenden dos criterios para definir lo que encierra el concepto de información pública. Por un lado, se emplea en un sentido estricto la noción de información pública, circunscrito a aquella que o bien está contenida en documentos 
formalizados -contenidos en soporte de papel o electrónicos- emitidos por un órgano administrativo (por ejemplo, actos, resoluciones, actas, expedientes, contratos y acuerdos) así como también aquella información que ha sido elaborada con presupuesto público. Es decir, aquella que se ha producido gracias a la utilización de recursos públicos. De otro lado, el texto legal también expresa un criterio lato para abarcar dentro de la noción de información pública, a toda la información que detenta la Administración o que esté en manos de ella, con independencia de si se ha producido mediante el empleo de fondos públicos.

En el sentido restringido, se comprende que el fundamento para considerar la información como pública es que ésta sea expresión del ejercicio de una potestad pública o bien se haya producido gracias al empleo de recursos del Estado lo que le atribuiría la titularidad de la misma, estando subyacente la existencia de una facultad amplia de disponer de dicha información que, en definitiva, se justifica en los recursos públicos empleados para su obtención. Sin embargo, cabe también la posibilidad de que aun cuando la obtención de la información se haya realizado con presupuesto público el titular de esta información es privado, como sucede con los datos personales (letra ñ, artículo 2 de la Ley N. ${ }^{\circ} 19.628$ ), los cuales de acuerdo con el ordenamiento gozan de una protección especial.

En el sentido lato, la referencia del legislador a la información "que obre en poder de los órganos de la Administración” amplía el ámbito de la noción de información pública comprendiendo en ella, no sólo a la información producida con recursos estatales sino a la información que la Administración tiene en su poder, cualquiera sea su origen o procedencia, esto es, con independencia de que hubieran sido obtenidos por la misma Administración (con recursos públicos), o bien, que se la hubiese proporcionado directamente los particulares (por ejemplo, los usuarios de un servicio de salud o los beneficiarios de un subsidio) o terceros con obligaciones de información ${ }^{3}$. Se ha de advertir que una parte significativa de la información que posee la Administración no la genera ella sino que la obtiene directamente de los interesados en cumplimiento de deberes legales de información o con el propósito de cumplir con las exigencias para adquirir la calidad de beneficiarios de ciertas prestaciones públicas. Así, en virtud del sentido lato del concepto información pública, el volumen de información que queda incursa en esta noción, se multiplica inconmensurablemente.

3 Sobre los deberes de información como técnica de ordenación, nos hemos referido en Camacho (2007). 
En atención a estas dos acepciones que el concepto información pública puede expresar, se puede concluir que, en realidad, lo que ha buscado el legislador es utilizar el término en el sentido de aludir al régimen jurídico que se le aplica a la información que obra en manos de la Administración por cualquier motivo, es decir, toda la información que está en su poder está sometida al régimen de transparencia, y en principio afecto a la publicidad, salvo que se configuren las excepciones que admite el artículo 8 de la Constitución Política, debidamente desarrolladas por leyes de quórum calificado, dentro de cuya calificación se encuentran algunas disposiciones de la Ley N. ${ }^{\circ} 19.628$, las que según ya hemos argumentado permiten fundar excepciones a la publicidad.

A este respecto, el Consejo para la Transparencia ha tenido pronunciamientos claros que aplican la definición que establece la Ley $\mathrm{N}$. 19.628 sobre datos personales al tiempo que reconocen la titularidad de los mismos en la persona a la cual se refieren (decisiones N. A29-09, C48809 y C407-09). Estos pronunciamientos se han referido a solicitudes de información sobre procesos de selección de personal impulsados a través del sistema especial de selección de los altos directivos públicos (Sistema de Alta Dirección Pública), regulado por la Ley N. ${ }^{\circ} 19.882$, llevados a cabo por la Dirección Nacional del Servicio Civil. En consecuencia, la doctrina que a través de sus pronunciamientos ha ido estabilizando el Consejo ha sido que:

1. Respecto de las evaluaciones (puntajes propios) o informes (por ejemplo, el informe psicosocial) que son relativos al propio peticionario y que se han construido (bien sea por los evaluadores o consultores externos o la DNSC), a partir de los antecedentes que el peticionario ha proporcionado, no corresponde que el servicio deniegue la información alegando afectación de derechos de las personas, pues los datos son del requirente.

2. Respecto de las referencias de terceros, se estimó que éstas son reservadas. Conclusión a la que llega el Consejo después de aplicar un test de daño y confrontar el derecho de acceso y el interés público que puede afectarse por la divulgación. Entendemos que en este caso, el fundamento se encuentra fuera del ámbito de la protección de datos personales, radicándose más bien en la búsqueda de cautelar la objetividad del proceso de selección para lo cual es necesario que a aquellos a los que se solicita referencias de terceros puedan expresarlas con la garantía de la reserva de sus opiniones.

3. Respecto de la información solicitada sobre postulantes distintos al requirente, se hace distinciones. Así, el Consejo suscribe el criterio del Instituto Federal de Acceso a la Información de México en virtud del 
cual las evaluaciones e informes de los postulantes no seleccionados son reservados. Mientras que respecto de los postulantes que llegan a la selección final, especialmente, el seleccionado, el Consejo estima necesario adoptar "un estándar de escrutinio público más alto" en beneficio del control social que debe haber respecto de los procesos de selección en el SADP, de modo que permita acreditar la idoneidad para desempeñar el cargo. Eso sí, la publicidad debe hacerse con la salvedad de los datos sensibles, los cuales deberán tarjarse en virtud del principio de divisibilidad de la letra e del artículo 11 de la Ley de Transparencia. El criterio del Consejo en este caso, aunque no lo dice explícitamente, supone que luego de haber realizado una ponderación de un lado, entre el derecho de acceso y de otro, el derecho a la vida privada y el derecho a la protección de datos, ha optado por la publicidad. Este criterio ha sido ratificado por la Corte de Apelaciones de Santiago mediante sentencia de 4 de marzo de 2011, recaída en recurso de reclamación contra la decisión del Consejo en la causa Rol N. ${ }^{\circ} 3457-2010$.

\section{LA PROTECCIÓN DE DATOS NOMINATIVOS NO SENSIBLES}

Es interesante destacar que el Consejo para la Transparencia ha tenido pronunciamientos claramente favorables al derecho de protección de datos personales. Un ejemplo en este sentido, constituye la decisión que tomó ante el reclamo presentado por denegación de entregar copia íntegra de los expedientes de multas cursadas por la Dirección del Trabajo solicitadas por el respectivo empleador (decisión N. ${ }^{\circ}$ A53-09). En este caso, era previsible que la revelación de la identidad de quienes denunciaron y declararon en dichos procedimientos (trabajadores) podría afectar los derechos de esas personas, por lo que sólo acogió el reclamo del solicitante aplicando el principio de divisibilidad. Atendiendo al vínculo de dependencia que genera la relación laboral,

[...] el Consejo reconoce que cierta parte de la información contenida en los expedientes solicitados por el reclamante podría contener datos personales de terceros -e incluso sensibles-, que deberían ser protegidos de acuerdo a los arts. $2^{\circ}, 4^{\circ}, 7^{\circ}, 10$ y 20 de la Ley N. ${ }^{\circ}$ 19.628, de 1999, sobre protección de la vida privada o protección de datos de carácter personal (considerando N. ${ }^{\circ} 12$ ).

En otras situaciones relativas a solicitudes de copia de sumarios administrativos y sumarios sanitarios, el Consejo ha hecho prevalecer el interés público que la publicidad de este tipo de procedimientos sancionadores posee, por lo que ha preferido el valor de la transparencia. 
Así, ha fallado que

Respecto de la posible afectación del derecho a la vida privada de los terceros con la divulgación de esta información, es menester reproducir los fundamentos sostenidos por este Consejo en su decisión C411-09, de 11 de diciembre de 2010 [...] a saber: c) este Consejo entiende que el archivo de los expedientes disciplinarios al interior de un organismo.. no constituiría un tratamiento de datos personales según el tenor del artículo $1^{\circ}$ de la Ley N. ${ }^{\circ} 19.628$, por lo que el art. 21 de dicha Ley (conforme al cual los organismos públicos que sometan a tratamiento datos personales relativos a condenas por delitos, infracciones administrativas o faltas disciplinarias, no podrán comunicarlos una vez prescrita la acción penal o administrativa, o cumplida o prescrita la sanción o la pena) no impediría entregar la copia de un decreto o resolución como los solicitados en este caso (considerando N. ${ }^{\circ}$ 6, letra c, decisión N. ${ }^{\circ}$ C617-09).

\section{REFLEXIONES FINALES}

El derecho a la protección de los datos personales traspasa la clásica división del ámbito de lo público y lo privado, pues en ambos campos es necesario cautelarlo. El Consejo para la Transparencia, aun con las restricciones que tiene el marco normativo de la Ley N. ${ }^{\circ} 19.628$ ha venido ejerciendo control sobre los órganos de la Administración del Estado, armonizando la aplicación de la Ley N. ${ }^{\circ} 19.628$ con la Ley de Transparencia. En estos casos, el Consejo ha debido recurrir con mayor énfasis al test de daño o al análisis de proporcionalidad para determinar cuál derecho ha de prevalecer, lo que le ha permitido desarrollar una labor interpretativa compatibilizadora de los valores en juego que ha ido afinando.

La jurisprudencia dictada por el Consejo en materia de protección de datos personales constituye un camino que sirve de importante referente para la actuación de los organismos de la Administración pública. Es por esta razón que interesa seguir avanzando en la sistematización de los criterios jurisprudenciales del Consejo que sirvan en la construcción de estándares de actuación para los organismos públicos, labor a la cual se ha pretendido contribuir con el presente trabajo. 


\section{REFERENCIAS}

Arrieta, R. (2009). Chile y la Protección de Datos Personales: Compromisos Internacionales. En Varios Autores, Chile y la Protección de Datos Personales. ¿Están en crisis Nuestros Derechos Fundamentales? Santiago: Ediciones Universidad Diego Portales.

Camacho, G. (2007). La Actividad de la Administración del Estado. México: UNAM.

(2010). Algunas Precisiones sobre el Concepto de Información Pública. En Letelier R. y Rajevic, E. (Eds.), Transparencia en la Administración Pública. Santiago: Legal Publishing.

Corral, H. (2000). Configuración Jurídica del Derecho a la Privacidad II: Concepto y Delimitación. Revista Chilena de Derecho, 27 (2), 331-355.

Cruz, F. J. (2011). Protección de Datos y Servicios Globales: ¿Regulación o Incentivo? En Expansiva, Reflexiones sobre el Uso y Abuso de los Datos Personales en Chile. Santiago: Expansiva.

Ferreiro, A. (2009). Estrategias Emergentes para el Desarrollo de la Protección de Datos en Chile. Ponencia presentada en el VII Encuentro Iberoamericano de Protección de Datos, 3 de noviembre, Madrid, España.

Figueroa, G. (1998). Derechos de la Personalidad en General: Concepción Tradicional. Revista de Derecho de la Pontiicia Universidad Católica de Valparaiso, XIX, 21-34

International Data Corporation (IDC). (2009). La Industria de Servicios Globales en Chile. Estudio de IDC Elaborado para CORFO. Santiago: IDC.

Rajevic, E. (2011). Protección de Datos y Transparencia en la Administración Pública Chilena: Inevitable y Deseabe Ponderación. En Expansiva, Reflexiones sobre el Uso y Abuso de los Datos Personales en Chile. Santiago: Expansiva.

Serna de la Bilbao, M. N. (2009). Institucionalización de la Protección de Datos de Carácter Personal. En Expansiva, Reflexiones sobre el Uso y Abuso de los Datos Personales en Chile. Santiago: Expansiva.

Sparkes, A. W. (1981). The Right to Be Let Alone: A Violation of "Privacy". En Curiel, J. (Comp.), Symposia I. Memoria del X Congreso Mundial Ordinario de Filosofía del Derecho y Filosofía Social, Volumen V. México: 
UNAM.

\section{Leyes e instructivos}

Ley N. ${ }^{\circ}$ 19.628, sobre Protección de la Vida Privada, República de Chile.

Ley N. ${ }^{\circ}$ 20.285, sobre Acceso a la Información Pública, República de Chile.

Instructivo General N. ${ }^{\circ}$, sobre Transparencia Activa, sancionado por el Consejo para la Transparencia, República de Chile.

Recibido: 23-04-2014

Aceptación de la versión final: 03-06-2014 